\title{
I
}

European Investment Bank

Economic and Financial Report 2001/03

\section{The euro and capital markets: A new era}

\author{
Eric Perée and Alfred Steinherr
}

European Investment Bank

100, blvd. Konrad Adenauer

L-2950 Luxembourg

Email: infoefs@eib.org

ECONOMIC AND FINANCIAL REPORTS are preliminary material circulated to stimulate discussion and critical comment. Quotation of material in the Reports should be cleared with the author or authors.

The views expressed are those of the individual authors, and do not necessarily reflect the position of the EIB. Individual copies of the Reports may be obtained free of charge by writing to the above address or on-line from www.eib.org/efs/pubs.htm 


\section{The euro and capital markets: A new era ${ }^{1}$}

by Eric Perée and Alfred Steinherr ${ }^{2}$

\section{Introduction}

In its publication "One market, one money" the European Commission presented its assessment of the likely economic gains to be obtained from the adoption of the single currency (European Commission 1990). Three broad classes of benefits were expected to result from EMU. Firstly, the disappearance of exchange rate variability and reduction of transaction costs in intra-European cross-border transactions should increase micro-economic efficiency. Secondly, the more stable macroeconomic environment and the focus on fiscal rectitude and price stability should lead to a growth-oriented macroeconomic environment. Finally, the creation of a large homogeneous financial zone should make the euro zone more resilient to external shocks and lead to a currency that could challenge the worldwide status of the US dollar.

Many observers assess the financial success of EMU with respect to the external value of the euro. The weakening of the euro against the main international currencies since January 1999 has been taken as a sign of poor performance. While such a yardstick has the attraction of easy monitoring, it is nevertheless a meaningless reference point. No one would want to base a judgement on whether the United States is well served by having the dollar on short-term gyrations of that currency in the foreign exchange market. Whether the euro is a success or not should be based on meaningful economic indicators capturing the essential features of EMU. Has the euro maintained a stable internal value (i.e. low inflation)? Has it led to higher economic efficiency in the EU? Has it sheltered the EU economy from external turbulences? While the performance of a monetary arrangement cannot be assessed in confidence from experience over a period of just two to three years, it should be noted that, despite a large series of economic shocks in the world economy in the second half of the 1990s, external

Forthcoming in the special issue "European Monetary Union and Beyond" of The World Economy, Volume 24(10), November 2001.

2 The authors are adviser and Chief Economist with the European Investment Bank, respectively. Kristian Uppenberg and Federico Galizia provided excellent data support. E-mail: e.peree@eib.org 
financial turbulences have not reverberated inside the European Union. This is in sharp contrast with the early 1970s when the monetary unification project mapped in the Werner report was put off track by the oil crisis of 1973.

Even if it is obvious that the introduction of the euro represents a fundamental change in the monetary organisation of the European Union, it is nevertheless extraordinary that the original analysis of the European Commission completely disregarded the potential efficiency gains in the European financial organisation that would result from EMU. In recent years, however, the European Union has come to realise that the success of EMU also depends on the development of a better financial architecture. Initiatives to develop the venture capital industry, catering to the needs of innovative and fast growing firms, or to improve the functioning of the government bond market (European Commission, 2000) are representatives of such a shift in attitude.

The continental European financial architecture has traditionally been organised around banks. In the last two decades, traditional banking intermediation from deposits to loans has weakened, whilst capital markets have gained in importance. This is sometimes described as the "Americanisation of finance" (Steinherr, 1998) even if in the European context this has, so far, been essentially achieved through the transformation of the activities performed by banks and not via the emergence of a set of new and different financial intermediaries. While there is a wide body of literature looking at the pros and cons of bank-based vs. market-based finance, it not clear than one polar system necessarily dominates. For example, Davis (2001) supports the view that, as the services provided by banks and the capital market are imperfect substitutes, financial systems where banks and the capital market exist alongside provide a better shock absorption capacity to the economy.

This paper is organised as follows. Section 2 examines the forces that have changed the financial landscape at the world level over the last two decades. Section 3 summarises the arguments of how the introduction of the euro should add to these broader economic forces in reshaping euro financial markets. Section 4 verifies whether the actual experience since January 1999 has been in line with the ex ante expectations. Most of the analysis will be based on developments of the bond market. ${ }^{4}$ Section 5 offers some conclusions. 


\section{The changing worldwide financial landscape}

EMU was expected to lead to deep changes in the way finance is organised in Europe. However, finance has undergone profound changes in the last two decades and there is no clear sign that the process of change has come to an end. Therefore, to avoid attributing to the euro some changes resulting from broader forces, it is useful to see how the world environment for finance has changed in the last two decades or so. Naturally, EMU in most cases would amplify or/and accelerate these forces.

The driving forces for the evolution of finance over the last two decades can be grouped into seven broad classes: technology, advances in finance theory, retrenchment of the state in the provision of finance, free capital flows, introduction of worldwide financial standards, institutionalisation of management of savings and demographic changes. (see for example BIS 2001)

Without the rapid and continuous advances in information and telecommunication technology, finance, as we know it currently would have been impossible. Massive increases in computing power and faster data transmission enabled the application of new financial theory, facilitated profound advances in risk management and the unbundling of financial risks.

The wholesale dismantling of restrictions to capital flows as well as a lower involvement of public authorities in the provision of financial services, although at different speed across countries, have made the finance industry much more responsive to market forces. This has been accompanied by the introduction of worldwide standards in most fields of finance (the Basle capital agreement for banks is just one example).

In most developed countries, there has been a tremendous shift toward institutionalised management of savings. An ever-growing share of financial assets is nowadays controlled by professional asset managers, irrespective of whether they operate within banking conglomerates or outside of banks. This process has certainly not run its full course as the 
prospective ageing of population in most developed countries, by putting pay-as-you-go pension systems under strain, will reinforce the importance of professional asset managers.

The overall consequence of these forces is that the relative weight of capital market activities has increased tremendously compared to traditional banking intermediation.

\section{How and why EMU changes the world of finance in Europe}

The evolution of finance is essentially the consequence of the interplay of economic forces among economic agents in need of raising funds, savers, regulation and available technology. There is no reason to suspect that regulation and technology would be crucially dependent on EMU. So let us consider how the economic landscape prompted by EMU should change the behaviour of investors. At the end of the day, borrowers and the infrastructure will have to adjust so as to satisfy the needs of investors.

Firstly, the monetary philosophy underpinning EMU is that aggregate price stability is a useful goal and that inflation cannot enhance economic growth and efficiency in the medium term. Stable and low inflation should reduce the economic risk, driving down risk premia, and ultimately enabling investors to adopt longer time horizons for their investment. This should lead to the development of an "equity-based" culture.

Secondly, the adoption of the single currency in most of the European Union eliminates currency risk in cross border investment decision. As noted by Brookes (1999) performance of cross border investments prior to the euro was mainly driven by country specific factors. In a nutshell about three quarters of the performance of cross border investment was ultimately related to exchange fluctuations and domestic monetary policy. As the exchange rate factor disappears with EMU and monetary policy is conducted for the whole euro-zone, past investment strategies break down. For example, Brookes shows that the potential excess performance, for a given level of risk, that can be obtained by relying on past cross border asset allocation rules shrinks by about three-quarters with the introduction of the euro. In other words, asset managers and investors will have to adopt a different investment strategy. For example, equity investment will shift away from country factors in favour of sectoral allocations and bond investments should be expected to be attracted to more credit risk (emergence of a corporate bond market) and more arbitrage along the yield curve. 
Thirdly, the replacement of national currencies by the euro should lead to the disappearance of a regulatory driven "home bias" imposed on many institutional investors, facing strict limits on the extent of currency mismatches that they are allowed to bear. For example, in many European countries, life-insurance companies (one of the largest investors' group) are prevented from running currency risk. Hence they are forced to invest their reserves in the currency in which their liabilities are denominated. This led to two consequences: financial markets were segmented along national currency lines and, as the size of most national markets is small, liquidity was rather poor. The disappearance of national currencies and their replacement by the euro removed overnight market fragmentation and widened considerably the set of investable securities. This should lead to the convergence of returns (for a given risk) across the zone, much higher levels of liquidity and much bigger cross border investment flows.

The fragmentation along national currency lines, differences in monetary policies and exchange rate risk had wide-ranging consequences. Firstly, credit risk analysis and equity markets were under-developed. Secondly, the bond market in nearly all EU country was dominated, if not fully controlled by the government securities and public sector institutions. Thirdly, the only segment of the bond market controlled by the private sector was made of securities issued by the financial industry.

\section{How financial markets have changed with EMU.}

Let us now check whether the changes expected from the introduction of the euro are already visible less than three years after the introduction of the single currency.

The government bond market has traditionally been the dominant segment of the bond market. The removal of the "captive investors' base" that most governments enjoyed prior to EMU has made place for a much more competitive environment. National treasuries have had no choice but to improve the attractiveness of their securities. Table 1 shows how the sizes of 10-year benchmark government bonds issued by the three largest countries of the euro-zone have changed in the period 1996-2001. These three countries have the largest funding needs. The issue size of government bonds in 1996 is fairly representative of the 
situation before national treasuries changed the financing approach in the run-up to EMU. With the notable exception of France that had already taken steps to modernise its debt management policies, the size of the largest government benchmarks in both Italy and Germany was about EUR 10bn and the trading activity in these bonds was relatively low. As the euro became a distinct prospect, both Germany and Italy increased substantially the size of individual bond issues so as to provide investors with adequate liquidity. Nowadays, benchmark government bonds of the three largest euro-zone countries range between EUR 20 and $25 \mathrm{bn}$. For the sake of comparison, US benchmark Treasury bonds, before the cut in individual issues prompted by the budget surplus, had an individual size of about USD 15bn.

Table 1: Size of benchmark government bonds (in billion euro)

\begin{tabular}{|l|cccccc|}
\hline & 1996 & 1997 & 1998 & 1999 & 2000 & 2001 \\
\hline Germany & 12.8 & 15.3 & 15.0 & 20.0 & 20.0 & 24.0 \\
France & 18.7 & 21.8 & 25.3 & 24.0 & 18.0 & 19.7 \\
Italy & 8.7 & 14.7 & 22.8 & 23.0 & 21.1 & 18.7 \\
\hline
\end{tabular}

Note: Largest outstanding 10 year government in each year, 2001 to end September Source: Bloomberg

National treasuries have taken additional steps to improve the attractiveness of their securities. They have harmonised the characteristics of their bonds (for example, adoption of similar coupon calculation conventions) and have become much more transparent in their issuing policies (pre-announcement of issue calendars, increase in outstanding securities by re-openings).

Smaller European countries have lower refinancing requirements and it would be difficult for them to aim for the benchmark size of the largest ones. However, they have not remained inactive. They have taken steps to improve the liquidity of their securities. For example Spain has focused its borrowing programme on maturities where the largest countries are not very active. The Netherlands and Belgium have restructured their debt through buy-backs and exchange offers to reduce the number of government bonds and to consolidate them into larger issues. In both countries the target size of benchmark government bonds stands at around EUR 10bn, about twice as large as before. Several countries (Belgium, Austria and Portugal) have also aimed to reach a wider investors' base by launching the original (large) tranches of new bond issue through syndication. This has allowed them to tap pools of funds 
that otherwise would not have been available. Ireland provides one of the most striking examples of the efforts to improve the liquidity of its bonds. In 1999, The Irish National Treasury Management Agency exchanged nearly all the government bonds quoted on the stock exchange (which had features that restricted their marketability) for new benchmarks of $3,5,10$ and 16 years maturity.

The question arises whether the gains obtained by some countries are not offset by the losses suffered by others. This is unlikely to be the case. Confronted with the forces of competition national treasuries have vastly improved the attractiveness of their securities. Together with the credit-enhancing feature of the Stability and Growth Pact that should prevent the unsustainable build-up of public debt, these adjustments have led to relatively small yield spreads between European sovereigns. In the 10-year segment of the bond market yield spreads of Euro-zone government bond with respect to Germany range from 10 to $35 \mathrm{bp}$.

There are essentially two ways open to bond investors looking to enhance return. The first is to move along the yield curve. The second is to take on more credit risk. The first approach has always been available within the EU, but the liquidity was not necessarily sufficient to make this strategy viable. The improvement in the government bond market renders this approach possible. The option of more credit risk was mostly absent. The EU bond market was essentially the preserve of the public sector and of high quality financial institutions. Since the introduction of the euro there has been a remarkable growth of the non-government bond market. Table 2 provides the structure of non-government outstanding bonds by main classes of borrowers. It should be noted that the absolute size of the non-government bond market in US dollars exceeds that of the euro.

Table 2: Distribution of outstanding non-government bond markets ( $\%$ of total)

\begin{tabular}{|l|ccc|ccc|}
\hline \hline & \multicolumn{3}{|c|}{ USD } & \multicolumn{3}{c|}{ EUR } \\
\cline { 2 - 7 } & 1995 & 2000 & difference & 1995 & 2000 & difference \\
\hline Corporations & 28.5 & 24.8 & -3.7 & 8.1 & 16.3 & 8.2 \\
Financial institutions & 18.9 & 20.8 & 1.9 & 56.3 & 49.2 & -7.0 \\
Collateralised debt & 39.6 & 39.2 & -0.3 & 19.5 & 26.1 & 6.5 \\
Non govt. public sector & 11.5 & 13.7 & 2.2 & 11.6 & 5.3 & -6.3 \\
Supranationals & 1.6 & 1.5 & -0.1 & 4.4 & 3.1 & -1.3 \\
\hline
\end{tabular}

Source: BIS 2001 
As Table 2 clearly indicates, there has been no dramatic shift in the overall structure of the USD bond market between 1995 and 2000. By contrast the euro market has undergone significant changes. The share of the outstanding bonds of corporations has doubled to $16 \%$ in only five years, but it still trails that of the US dollar market. The share controlled by banks has been reduced to about $50 \%$, while that controlled by collateralised debt (essentially German Pfandbriefe (mortgage backed securities) and securities structured in a similar way in other European countries) has increased.

The evolution of outstanding stocks as depicted in Table 2 reacts at slow speed as the pattern of new flows changes. To better understand whether there are visible effects of EMU we turn to flow data. Ideally one would like to analyse the flow of borrowings and their main characteristics and compare the market in euro with an external benchmark (say the USD bond market). There are several alternative data sources on bond market activity (Capital Data Bondware, IFR, BIS, European Commission). However, the geographical coverage and the details available differ substantially. No data source dominates the others in all respects. We shall rely on the European Commission data to assess the structure by borrowers of bond issues in euro since January 1999. Subsequently we shall rely on IFR data to look at the main characteristics of individual transactions and for the comparison with the USD market.

The data in Table 3 clearly indicate that there have been quite significant changes in the structure by borrowers in the euro capital market. Let us assume that if the euro had not come into being, the average structure of flows in the euro-zone bond market would have remained as given by the structure presented in Table $2 .{ }^{5}$ Compared to such a scenario there have been dramatic shifts. The most important is that the corporate sector has massively increased its direct calls on the bond market. Compared with the $8 \%$ market share of non-government outstanding bonds in 1995, the corporate sector has captured about a fifth of the total issuance since the launch of the euro. A second feature is that the share of new bond issues originated by banks is substantially lower than in the past while the collateralised bond market has been growing sharply. Some of this growth is related to changes in banking activity. Instead of holding loans on their balance sheet and refinancing them through bond

There is no reason to suspect that in the long-term flow data would significantly diverge from outstanding stock. This would only be the case if the maturity structure of new issues would diverge significantly across broad classes of borrowers. Of course, we are also assuming that the structure of outstanding stocks in 1995 is at its medium-term equilibrium. 
issues, banks have embarked into securitising some of their loans. Finally, supranationals have reduced their calls on the euro bond market while regional and local authorities have started to tap the market. It should be observed that the structure by borrowers of new issues in euro is rather close to that of outstanding bonds in the USD. The notable difference is that in Europe banks play a larger role than in the US and the converse is true for collateralised bonds. This is not surprising as the participation of US banks in credit creation is much lower than in Europe, while that of other providers of credit outside the banking sector is much more developed in America.

Table 3: Structure by borrowers of non-government bond issues in euro

\begin{tabular}{|l|ccc|ccc|}
\hline \hline & \multicolumn{3}{|c|}{ Amount issued (EUR bn) } & \multicolumn{4}{c|}{ Share of total } \\
& 1999 & 2000 & 2001 & 1999 & 2000 & 2001 \\
\hline Local agencies and supranationals & 70.5 & 70.5 & 57.9 & $9.0 \%$ & $10.1 \%$ & $10.3 \%$ \\
Collaterralised bonds & 294.6 & 241.4 & 145.8 & $37.5 \%$ & $34.6 \%$ & $26.1 \%$ \\
Financials & 280.5 & 249.3 & 197.4 & $35.7 \%$ & $35.7 \%$ & $35.3 \%$ \\
Corporates & 140.3 & 136.5 & 158.4 & $17.9 \%$ & $19.6 \%$ & $28.3 \%$ \\
\hline Total non government & 785.9 & 697.7 & 559.6 & $100.0 \%$ & $100.0 \%$ & $100.0 \%$ \\
\hline
\end{tabular}

Note: 2001 up to the end of August

Source: European Commission

While the evidence presented so far suggests that the euro bond market is converging to US standards, we now examine whether this also holds for the characteristics of individual bond issues. We rely on the IFR Platinum data and consider only international bonds. An obvious point for comparison is the size of bond issues. In the period January 1999 to August 2001, the median bond issue size in euro is EUR $200 \mathrm{~m}$ and in dollar USD $200 \mathrm{~m} .{ }^{6}$ Table 4 provides another picture of the size distribution of bond issues. There are relatively more issues in dollar in the smaller (less than USD 100m) and larger (more than USD 1bn) size brackets than in euro. In euro, there are relatively more middle-sized issues ${ }^{7}$ : issues in euro are more frequent in the intermediate segment ranging from $100 \mathrm{~m}$ to $500 \mathrm{~m}$.

As size may vary considerably, the median is probably a better measure than the average. We discuss later the total size distribution.

7 One should note, however, that before the introduction of the euro, bond issues for amounts in excess of DEM $1 \mathrm{bn}$ or FRF 3bn (approximately EUR 500m) were considered to be of a very large size. 
Table 4: Size distribution of new international bond issues in euro and USD.

\begin{tabular}{|l|r|r|r|r|}
\hline \hline & \multicolumn{2}{|c|}{ EUR issues } & \multicolumn{2}{c|}{ USD issues } \\
\cline { 2 - 5 } & amounts & no of issues & amounts & no of issues \\
\hline $0-99 \mathrm{~m}$ & $2.94 \%$ & $24.56 \%$ & $2.47 \%$ & $28.88 \%$ \\
$100-249 \mathrm{~m}$ & $12.60 \%$ & $29.41 \%$ & $6.98 \%$ & $22.61 \%$ \\
$250-499 \mathrm{~m}$ & $19.61 \%$ & $22.09 \%$ & $12.04 \%$ & $17.98 \%$ \\
$500-999 \mathrm{~m}$ & $24.96 \%$ & $15.04 \%$ & $19.67 \%$ & $15.42 \%$ \\
Above $1 \mathrm{bn}$ & $39.89 \%$ & $8.90 \%$ & $58.84 \%$ & $15.11 \%$ \\
Total & $100.00 \%$ & $100.00 \%$ & $100.00 \%$ & $100.00 \%$ \\
\hline
\end{tabular}

Source: Thomson Financial IFR, IFR Platinum CD-Rom

Figure 1 provides a graphical description of the distribution by size of international bond issues in euro and in dollar. The Gini index for USD stands at 37\% while that of the euro, at $42 \%$, indicates a slightly lower level of size inequality in euro. It should be observed that all the above statistics on size relate to the individual size of each transaction. It is not necessarily an accurate indicator of the outstanding amounts as they can be increased over time by issuing further tranches that, sharing all the characteristics of the original bond, are merged into a bigger issue. This is a technique that has been used by many of the frequent borrowers. In addition, several large borrowers have embarked onto more formalised programs of borrowings to make their securities more attractive to investors.

Figure 1: Distribution by issue size in EUR and USD (1999-2001)

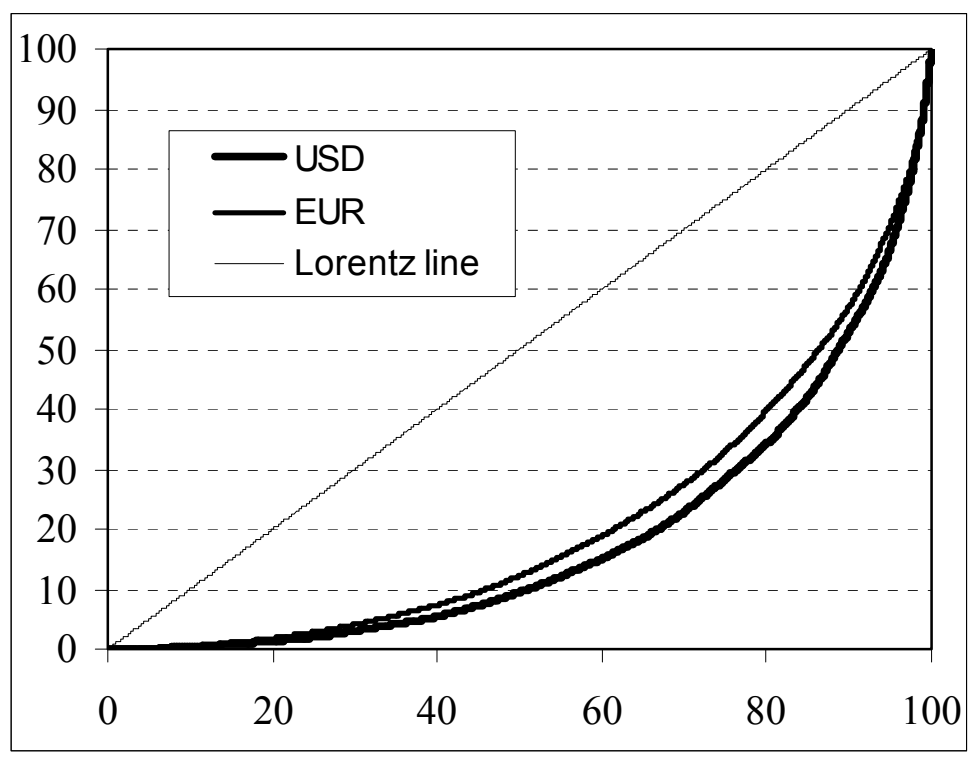

While we have seen that the corporate bond market has developed with EMU and that the size structure of euro denominated bonds has evolved toward the US level, it is also worth looking at the characteristics of the largest corporate deals. In both the United States and in 
Europe, supranationals and public agencies (including Pfandbriefe) have long been the providers of the largest issues. Tables $5 \mathrm{a}$ and $5 \mathrm{~b}$ provide the list of the ten largest international bond issues in dollar and euro, respectively. The publicly sponsored institutions in the United States, mortgage banks in Germany and several large financial institutions represent a large fraction of top-tier issuers. Table 5 only includes non-financial corporations and their financial subsidiaries as well as emerging market borrowers. The largest international bond issue over the last three years was done in euro by a subsidiary of Olivetti at the time it took over Telecom Italia. As the data in Table 5 clearly shows, the issue size of the largest individual corporate transactions in euro and dollar are fairly similar. On closer examination, however, two differences emerge: Firstly, the maturity range of the large corporate bond issues is much narrower in euro than in dollar. The longest maturity in euro stands at 7 years, while in dollar it goes to 40 years. ${ }^{8}$ Secondly, the vast majority of the large corporate transactions in euro are made by the telecom sector. In the US, the telecom sector has also been a large borrower, but the sectoral diversity is clearly wider.

Table 5a: Largest corporate international bonds since 1999 in USD.

\begin{tabular}{|c|c|c|l|c|}
\hline \hline Maturity Date & Launch Date & Issue size & Issuer/Borrower Company Name & Maturity \\
\hline 7-Sep-01 & 9-Aug-00 & 6000 & Unilever PLC & 1 \\
17-Aug-40 & 10-Aug-00 & 5157 & Brazil, Republic of Brazil & 40 \\
28-Oct-09 & 20-Oct-99 & 5000 & Ford Motor Credit Co & 10 \\
17-Nov-20 & 14-Nov-00 & 4657 & Tyco International Ltd & 20 \\
15-May-31 & 8-May-01 & 4600 & WorldCom Inc & 30 \\
16-Jul-04 & 8-Jul-99 & 4000 & Ford Motor Credit Co & 5 \\
1-Aug-05 & 26-Jul-00 & 4000 & Ford Motor Credit Co & 5 \\
15-May-11 & 8-May-01 & 4000 & WorldCom Inc & 10 \\
1-Mar-11 & 7-Mar-01 & 3500 & France Telecom SA & 10 \\
15-Jun-30 & 27-Jun-00 & 3500 & Deutsche Telekom International Finance BV & 30 \\
\hline
\end{tabular}

Source: Thomson Financial IFR, IFR Platinum CD-Rom. Data exclude bonds of supranational, banks and financial institutions and cover the period January 1999 to August 2001.

It should be observed that the wave of long maturity transactions that swept through the US corporate bond market in 2000 was also driven by the sharp reduction in long-term borrowing of the US Treasury, confronted with growing budgetary surpluses. 
Table 5b: Largest corporate international bonds since 1999 in EURO.

\begin{tabular}{|c|c|c|l|c|}
\hline \hline Maturity Date & Launch Date & Issue size & Issuer/Borrower Company Name & Maturity \\
\hline 30-Jun-04 & 3-Jun-99 & 7944 & Tecnost International NV & 5 \\
30-Jul-04 & 19-Jul-99 & 4500 & Tecnost International NV & 5 \\
11-Jul-06 & 2-Jul-01 & 4500 & Deutsche Telekom International Finance BV & 5 \\
12-Oct-01 & 29-Mar-00 & 4000 & France Telecom SA & 2 \\
14-Feb-06 & 30-Jan-01 & 4000 & General Motors Acceptance Corp & 5 \\
2-Feb-04 & 24-Jan-01 & 3500 & Ford Motor Credit Co & 3 \\
14-Mar-04 & 7-Mar-01 & 3500 & France Telecom SA & 3 \\
14-Mar-08 & 7-Mar-01 & 3500 & France Telecom SA & 7 \\
14-Dec-00 & 19-May-99 & 3250 & Repsol International Finance BV & 2 \\
1-Jan-05 & 14-Apr-99 & 3079 & Vivendi Environment & 6 \\
\hline
\end{tabular}

Source: Thomson Financial IFR, IFR Platinum CD-Rom. Data exclude bonds of supranational, banks and financial institutions and cover the period January 1999 to August 2001.

The above evidence suggests that the euro bond market has developed nicely and is coming close to sharing the main traits of the US international bond market. Further developments are likely for the following reasons. Firstly, venturing to the capital market requires time and the range of firms accessing the market will grow further over time. For example, in continental Europe about 500 firms are formally rated by the main rating agencies, while in the United States around 3,000 firms are rated (ECB, 2001b). ${ }^{9}$

One field in which the euro bond market has also recorded some success is in providing a source of funding for non-resident borrowers. The dollar has remained the currency of choice in international borrowings for most non-resident borrowers (outside the EU). However, several sovereigns from Latin America have raised funds in the euro bond market. The progress has been most spectacular with Eastern European sovereigns: most of these countries have an exchange rate policy that is linked to the euro, or at least their main economic ties are with the EU. Hence, borrowing in euro is seen as a sensible alternative.

We have observed above that the number of firms having a formal rating is rather limited. While the abolition of national currencies has widened investment possibilities over a much bigger zone, information has not necessarily kept pace. Borrowings that were previously based on local information and name recognition are no longer a viable alternative in the euro market. Borrowers have to appeal to a wider set of investors, which tend to rely on external credit ratings. Since the introduction of the euro the number of bond issues without a

A consequence of this has been that many US based corporates have come to tap the euro denominated bond market since the creation of the euro. 
formal credit rating has trended downwards. In addition, it should be stressed that acquiring or developing the credit risk analysis that is necessary in the new bond market requires time.

One feature of the euro bond market has attracted a lot of attention. Contrary to other bond markets where the sovereign is also responsible for issuing the currency, in the euro-zone there is no natural issuer that would be the reference issuer. While the first role of government securities is to fund the public debt at a low cost, government securities also provide some externalities as they serve for the pricing of bonds issued by other borrowers and they can be used as hedging instruments. (BIS 2001) In euro, there is no clear benchmark, although in the ten-year maturity and more recently in the five-year segment, German government bonds are the lowest yielding securities and the de facto benchmarks.

The existence of a government benchmark as a pricing reference and as a hedging tool is important if the yield structure of the various classes of borrowers tends to be stable with respect to these reference bonds. This is especially the case for hedging. Table 6 presents the evolution of the correlation between the yield difference between a borrower and the German benchmark and the same difference between the swap rate and the same German benchmark. The results of the table are quite instructive. The yields of euro-land sovereigns are essentially driven by the yield on the German bund. For the rest of the market the swap rate is the most important reference point. It is thus not surprising that actual pricing and hedging in the euro bond market is based on the German (or French) government bonds for sovereign borrowers and other borrowers are priced off the swap rate. This clearly shows that the absence of a unique incontestable government benchmark reference is not a real problem for the bond market.

Table 6: Correlation to swap spreads

\begin{tabular}{|l|c|}
\hline \multicolumn{1}{|c|}{ Issuer group } & Correlation \\
\hline Euroland sovereigns & 0.27 \\
EIB & 0.87 \\
KfW & 0.89 \\
AAA & 0.86 \\
AAA Pfandbriefe & 0.87 \\
AA & 0.82 \\
A & 0.74 \\
BBB & 0.57 \\
Swap & 1.00 \\
\hline
\end{tabular}

Note: Correlation between the yield difference between the issuer and the German bund and the yield difference between the swap rate and the German bund.

Source: Bloomberg, authors' calculations, Rated classes are made of a sample of securities from different borrowers. 
The fact that the euro bond market is made of two segments that have, in some sense, a life of their own has a big impact on the development of the derivatives market. Hedging of a government bond position with interest rate swaps entails a significant tracking risk; the same holds for investors holding corporate bonds hedged with government securities or government bond based derivatives contracts. Tables $7 \mathrm{a}$ and $7 \mathrm{~b}$ depict the evolution of the size of the interest rate swap market in the main currencies and the size of the most successful government bond-based futures contracts. It is easily seen that in both cases the euro derivatives are ranked in top position.

Table 7a: Notional amount of interest rate swap outstanding (USDbn)

\begin{tabular}{|l|cccccc|}
\hline \hline & Jun-98 & Dec-99 & Jun-99 & Dec-99 & Jun-00 & Dec-00 \\
\hline Euro & 13,576 & 16,461 & 17,483 & 20,692 & 22,948 & 21,311 \\
USD & 13,214 & 13,763 & 16,073 & 16,510 & 17,606 & 19,421 \\
JPY & 7,164 & 9,763 & 10,207 & 12,391 & 12,763 & 13,107 \\
Others & 8,414 & 10,028 & 10,309 & 10,498 & 10,808 & 10,829 \\
\hline Total & 42,368 & 50,015 & 54,072 & 60,091 & 64,125 & 64,668 \\
\hline
\end{tabular}

Source: BIS Quarterly Review of international and banking markets, various issues.

Table 7b: Turnover and outstanding contracts in government bond based futures contracts

\begin{tabular}{|l|c|cc|cc|}
\hline \hline \multicolumn{2}{|c|}{} & \multicolumn{2}{c|}{ Futures } & \multicolumn{2}{c|}{ Option } \\
\hline Contract & Exchange & Open interest & Total volume & Open interest & Total volume \\
\hline Euro-Bund & Eurex & 618,804 & $151,326,295$ & 842,146 & $26,291,123$ \\
Euro-Bobl & Eurex & 385,084 & $62,502,582$ & 136,688 & $2,436,491$ \\
Euro-Schatz & Eurex & 383,998 & $42,822,290$ & 149,077 & $1,954,183$ \\
US 30yr Treasury & CBOT & 405,409 & $62,750,843$ & 447,690 & $17,267,458$ \\
US 10yr Treasury & CBOT & 527,613 & $46,700,538$ & 605,817 & $10,629,021$ \\
US 5yr Treasury & CBOT & 358,012 & $23,331,981$ & 185,008 & $3,733,542$ \\
\hline
\end{tabular}

Source: Futures and Options Week Vol 6 Number 04/ 29January 2001

We have considered the changes in the bond side of the capital market. While the impact of the euro is clearly visible there, the equity market has also undergone massive transformations. Tsatsaronis (2001) shows that domestic factors have become much less important in driving stock market performance, which is becoming more dependent on sectoral factors. It is, thus, not surprising that cross-border sectoral mutual funds have been one of the most rapidly growing segments of the market since the launch of the euro. 


\section{Conclusions}

We have reviewed the development of euro capital market since the introduction of the euro. It emerged that the new currency has had profound effects on the European financial scene. Confronted with increased competition, European borrowers have had to meet the requirements of investors that are no longer captive in their national currencies. All borrowers have taken steps to improve the attractiveness of their securities and provide investors with enhanced liquidity.

The euro bond market has developed strongly and is getting closer to the structure of the US dollar market. This evolution should improve the financial allocation of capital throughout the European Union, supporting a more efficient economic system, and make the European economic more resilient to economic shocks.

In our view EMU was worth the effort and political risk on the basis of the gains from a more performing capital market alone. Public discussion has virtually neglected this aspect and has focused on the other sources of gain.

Despite the fact that, as argued by Lamfalussy (2001), the European capital market would benefit from a European regulatory and supervisory framework, we have endeavoured in this paper to show the dramatic improvements achieved so far, even without this desirable change. 


\section{$\underline{\text { References }}$}

Bank for International Settlements, 2001, "The Changing Shape of Fixed Income Markets", BIS Working Papers No.104, September.

Brookes Martin, 1999, "The Impact of EMU on Portfolio Management", in EIB Papers, 4(1), pp 19-34

Davis E. Philip, 2001, "Multiple Avenues of Intermediation, Corporate Finance and Financial Stability", IMF Working Paper WP/01/115, August

European Central Bank, 2001a, “The Euro Money Market”, ECB Occasional Papers, July.

European Central Bank, 2001b, “The Euro Bond Market”, ECB Occasional Papers, July.

European Central Bank, 2001c, “The Euro Equity Market”, ECB Occasional Papers, July.

European Central Bank, 2001d, "Review of the International Role of the Euro", September.

European Commission, (1990), "One Market, One Money", European Economy, 44, October.

European Commission, "Monthly and Quarterly notes on the euro-denominated bond markets", various issues.

European Commission, 2000, "Coordinated Public Debt Issuance in the Euro Area" (Report of the Giovannini Group), November.

European Commission, 2001, "Report of the Committee of Wise Men on the Regulation of European Securities Markets" (Lamfalussy Report).

European Commission, (2001), "EMU: The First Two Years", Euro Papers, 42, April.

Lamfalussy Alexandre, 2001, "Toward an Integrated European Financial Market", in the special issue "European Monetary Union and Beyond"of The World Economy 24(10), November.

Steinherr Alfred, 1998, Derivatives: The Wild Beast of Finance, John Wiley \& Sons, London

Tsatsaronis Kostas, 2001, "Market practice ahead of industrial structure in pricing euro area equities: country vs. sector effects", BIS Quarterly Review, March, pp 13-14. 